$\xi=$ 离

\title{
Prevalence of unintended pregnancy among antenatal care followers, in kersa woreda, estern hararghae, Ethiopia
}

\author{
Merhawi G Mdhin ${ }^{2 *}$, Tewelde Gebrehawerya ${ }^{1}$,Gezahagn Tesfaye ${ }^{2}$, Mariam Alemayehu ${ }^{3}$, Sultan Waritu ${ }^{4}$ \\ ${ }^{1}$ Haramaya University, School of Nurse, department of Midwifery, Harar, Ethiopia \\ ${ }^{2}$ Haramaya University, School of public health, Harar Ethiopia \\ ${ }^{3}$ SNNP Region, Cidama zone, Gedeb primary Hospital, SNNP, Ethiopia \\ ${ }^{4}$ Oromia Region, west Arsi zone, Gadedo Health center, Oromia, Ethiopia \\ *Corresponding authorE-mail: meriget12@gmail.com
}

\begin{abstract}
Introduction: Unintended pregnancy is an important Public health concern worldwide that affect women, families and society at large. An unintended pregnancy has been responsible for unplanned and mostly unwanted family unions that ultimately cause disrupted lifestyles, a source of conflict between individuals and families as well as discrimination against girl hence the objective of this study was aimed to assess the prevalence of unintended pregnancy and its cause among ANC followers.

Methodology: The study was conducted in kersa woreda, Eastern hararghae, Ethiopia from February to March, 2015. Facility based descriptive cross-sectional study was conducted among the sample of pregnant women visiting the randomly selected health facility. The source population was all pregnant women residing in kersa woreda and the study population was all pregnant women found in study area who visited health institution for ANC follow up. Our sample was 328 women, and respondents were selected using systematic random sampling. The data was cleaned, entered and analyzed using SPSS version 20.0.

Result: The magnitude of unintended pregnancy was 31.3\% of those, 82(25.6\%) was mistimed and $18(5.6 \%)$ was unwanted. Decision power, no radio, and not able to discuss with partner showed significant association. God's order, husband contraceptive disapproval, and lack of information on contraceptives were mentioned as main cause for current unintended pregnancy.

Conclusion: unintended pregnancy was prevalent in 31.3\%. Absence of radio, lack of information and lack of discussion with partner was significant predictors. Health information dissemination is needed to community residents, and local governors should ensure that accessible, affordable and acceptable contraceptive is in place.
\end{abstract}

Keywords: ANC Followers; Ethiopia; Prevalence; Unintended Pregnancy.

\section{Introduction}

Unintended pregnancies (UP) which is defined as pregnancies that have reported either as unwanted-no more children were desired or mistimed-occurred earlier than planned time (WHO, 2007).Unintended Unintended pregnancy has significant public health problems on women, children, families and societies at large. The issue presents in every society, and in some cases it is a source of anguish and difficult for families and individuals. An unintended pregnancy is responsible for unplanned and unwanted family unions, disrupted lifestyles, a source of conflict in the families as well as an integral part of the disadvantage and discrimination against the girl child (Stanford et al.1999).

The consequence of UP affects, both the mother and the born child who results in a live birth associated with household dysfunction and exposure to psychological, physical or sexual abuse during the woman's childhood (Cabral R 2003, Gipson JD 2008, and Burke AE 2010).Mother Mother with UP is associated with depression, anxiety and abuse (Hearst et al.2010). Furthermore, they are less likely to use any maternal and child health services, but rather they develop bad habit like alcohol and tobacco use. (Cabral R 2003 \& Holcombe E 2007). Unintended pregnancy also affects demographic trends and people's health and wellbeing (PAI, 2011).
Many women and couples in Ethiopia don't have the knowledge; tools or assistance needed to maintain their reproductive health and have the number of children they desire (Bankole A 2009 \& Guttmacher Institute.2010).According 2010). According to to report of Ethiopian demographic and health surveys 2011, 25 percent of currently married women had unmet need for contraceptives, 9 percent of births were not wanted and 16 percent of births were mistimed (ECSA, 2011).

\section{Methodology}

The study was conducted from February to March, 2015 in kersa woreda which is $475 \mathrm{~km}$ away from the capital city-Addis Ababa. The woreda has total population of 199,603 of which 99,027are females and expected number of pregnancies in the woreda is 7,584 . The woreda has 7 health centers and 38 health posts. About 13 public health officers, 55 nurses, $14 \mathrm{mid}$ wives nurses, 11 lab technicians, and 74 health extension workers are currently deployed in the woreda.

Facility based descriptive cross-sectional study was applied. The source populations were all pregnant women residing in kersa woreda while the study populations were all pregnant women who follow ANC on the randomly selected health facilities. The study unit was pregnant women visiting randomly selected health facili- 
ties during the time of data collection for ANC follow up. The sample size was determined by single population proportion formula considering prevalence of $27.9 \%$ for unintended pregnancy in kersa woreda, (Kassa et al. 2012), a 5\% margin of error, a 95\% confidence level, and $10 \%$ non-response rate; giving total sample of 310. Since the total number of pregnant women in the were was about 7584 which are $<10,000$, we use correction formula to get the final sample size and this gives 298 adding $10 \%$ none response rate the final sample was 328 .

First Health facilities were selected by simple random sampling; then total sample were allocated using probability proportional to size sampling (PPS) technique to the two selected health facilities. Finally the study subjects were selected by systematic random sampling technique, by setting a target on average of ten pregnant ANC followers per day per Health Center. After calculating the interval ( $\mathrm{K}$ value $=2$ ) which is the total Pregnant ANC followers in the selected health facility at specified time (1month ) divided by the allocated sample to each of the selected health facility through which every $\approx 2^{\text {nd }}$ pregnant women will be included after identifying the random starting number.

Questionnaire was prepared in English then it was translated to Amharic. The Amharic version questionnaire was used after pretest is made on $5 \%$ of the sample. Data were collected by direct face to face interview. The questioners includes the socio demographic characteristics, reproductive history and questions on KAP towards causes of unintended pregnancy. The Data was collected by two $4^{\text {th }}$ year public health students. During the data collection, questionnaires were checked for consistency and completeness. Each questionnaire was given a unique code by the investigators. Data was entered and cleaned by principal investigators before analysis. Frequency was used to check for missed values and outliers any errors identified at the time were corrected.

The dependent variables was unintended pregnancy and independent variable includes socio-demographic variables, contraceptive use/or failure, knowledge about unintended pregnancy.

The collected data were checked and edited for any incompleteness or inconsistency and it was coded, entered and cleaned and entered to SPSS version 20.0 for analysis. Finally, the data was presented by using statement, frequency, different tables and figures. Association between the dependent and independent variable were tested by using OR (odds ratio) and $95 \% \mathrm{CI}$ were used to measure strength of association between the two variables.

Ethical clearance was obtained from Haramaya University, college of medical and health science department of public health. A written official permission was sent to kersa wereda health center to secure permission. All study participants were informed about the purpose of the study and their rights. The data collection was started after verbal consent is assured from the participant. Data was kept confidentially.

Unintended pregnancy: are pregnancies that occurred when no children, or no more children, were desired or occurred earlier than needed by the partners. Unwanted pregnancy is defined as pregnancies that have occurred to the women who were not wanted to become pregnant. Mistimed pregnancy is considered for pregnancy, which has occurred without the wish of the women earlier than the specific time they need...Intended pregnancy is defined pregnancy that occurred to women who wanted a baby at the specific time they became pregnant.

\section{Result}

Out of 328 sampled ANC followers, 320 were interviewed making a response rate of $98.5 \%$. The age of respondents ranged from $15-$ 45years and nearly two third $(67.5 \%)$ of the respondents were Young adults (15-25 years) while one-third of them were in the age group of 25-34 year. Concerning religion, 265(82.8\%), 10.9\% and $5.6 \%$ were Muslim, Orthodox and Protestant respectively. $313(97.8 \%)$ of them were married. and, $198(61.9 \%)$ were rural residents. Regarding the educational status of respondents, $177(55.3 \%)$ reported they are uneducated (unable to read and write and informal education), 72(22.5) completed primary education, $32(10 \%)$ completed secondary education and $39(12.2 \%)$ of women attained diploma and above. About, 156(49.1\%) of the study participants were house wives, $28.1 \%$ were farmers, $11.9 \%$ were government employee and 11(3.4\%) were students (table 1).

Table 1: Socio Demographic Characteristic of Respondents in Kersaworeda, Eastern Ethiopia, 2015

\begin{tabular}{|c|c|c|c|}
\hline $\begin{array}{l}\text { Socio demographic } \\
\text { characteristics }\end{array}$ & & Frequency & $\begin{array}{l}\text { Percent } \\
(\%)\end{array}$ \\
\hline \multirow{6}{*}{ Age } & $15-25$ & 209 & 65.3 \\
\hline & $26-35$ & 106 & 33.1 \\
\hline & $36-45$ & 5 & 1.6 \\
\hline & Total & 320 & 100 \\
\hline & Single & 2 & 0.6 \\
\hline & married & 313 & 97.8 \\
\hline \multirow{3}{*}{ Marital status } & divorced/widowed & 5 & 1.6 \\
\hline & Total & 320 & 100 \\
\hline & orthodox & 35 & 10.9 \\
\hline \multirow{6}{*}{ Religion } & Muslim & 265 & 82.8 \\
\hline & protestant & 18 & 5.6 \\
\hline & Other & 2 & 0.6 \\
\hline & Total & 320 & 100 \\
\hline & $\begin{array}{l}\text { government employ- } \\
\text { ee }\end{array}$ & 76 & 23.8 \\
\hline & Private employee & 16 & 5.0 \\
\hline \multirow{7}{*}{$\begin{array}{l}\text { Partner's occupa- } \\
\text { tional status }\end{array}$} & Daily laborer & 16 & 5.0 \\
\hline & farmer & 198 & 61.9 \\
\hline & student & 12 & 3.8 \\
\hline & Don't know & 2 & 0.6 \\
\hline & total & 320 & 100 \\
\hline & house wife & 156 & 48.18 \\
\hline & $\begin{array}{l}\text { Government employ- } \\
\text { ee }\end{array}$ & 38 & 11.9 \\
\hline \multirow{5}{*}{$\begin{array}{l}\text { Respondent's occu- } \\
\text { pational status }\end{array}$} & Private employee & 13 & 4.1 \\
\hline & Daily laborer & 11 & 3.4 \\
\hline & farmer & 91 & 28.4 \\
\hline & student & 11 & 3.4 \\
\hline & total & 320 & 100 \\
\hline
\end{tabular}

From the total respondents, $256(80.6 \%)$ of them, had radio and $76(23.8 \%)$ of the respondents had television. Of all participants $166(51.9 \%)$ of them believe that they are medium in wealth status, $133(41.6 \%)$ believe that they are rich while $6.6 \%$ consider themselves as poor. Respondents were asked whether the facility where they get service is near or far, accordingly $111(34.7 \%)$, $133(41.6 \%)$ and $76(23.8 \%)$ believe that the facility is far, medium far, and near to them respectively. Of all respondents $301(96.8 \%)$ get their first pregnancy after they celebrate their $18^{\text {th }}$ year while $19(5.9 \%)$ of them were gotten before $18^{\text {th }}$ years-old. $32(10.9 \%)$ of respondents replied that they had experienced one or more abortion in previous times. From 220women who ever experienced pregnancy, $110(50 \%)$ of them get pregnant after3 or more years gap after their most recent pregnancy and 50\% of them get pregnant before 3 years gabs. Respondents were also asked about how many children they want additionally and about 222 (69.4\%) need 3-5 additional children. Participants were also asked about number of children they want to have in their life time based on this, $85.9 \%$ of total respondents replied that they want to have been greater than 3 child in their life.

Respondents were asked about the decision power on the number of children they want to have and $265(82.8 \%)$ of them replied that both wife and the husband decide together, $12(3.8 \%)$ said that the autonomy is in their husbands hand, and $10.3 \%$ said as God will.

From 320 respondents, 213(66.6\%) of them answered that they have information about unintended pregnancy while $35.4 \%$ do not have any information. Of these with information about UP, 176 $(82.7 \%)$ of them replied that they got the information from health extension worker, $90(42.3 \%)$ from media, $18(8.5 \%)$ from friends and $7(3.3 \%)$ from other sources. of those who have information about UP $185(86.8 \%)$ of them answered perfectly as it is to mean mistimed and unwanted. About 30.3\% don't know the possible causes of UP while, $130(40.6 \%)$ said it is due to carelessness and $103(32.2 \%)$ due to sexual assault (fig1). 
Women asked for their idea whether it is possible to prevent pregnancy or not, based on this, $270(84.4 \%)$ of the respondents think that it is possible to prevent pregnancy. Of those who believe that it is possible to prevent pregnancy by using family planning 176 $(55.0 \%)$, by avoiding unsafe sexual intercourse101(31.6\%), and by avoiding alcohol and substance use $65(20.3 \%)$ but $50(15.6 \%)$ of them think that it is impossible to prevent it.

Study participants were also asked whether they were used any method to prevent current pregnancy or not, besides $77(24.1 \%)$ of them were used family planning to prevent current pregnancy of those $74(96.1 \%)$ were used modern contraceptive. However, $243(75.9 \%)$ were not used any method for certain reasons; $172(70.6 \%)$ of them answered that it was because they need to give birth, $58(23.8 \%)$ were due to lack of information on importance of FP, 7 (2.9\%) of the respondents replied to that their husband did not allow them to use family planning method and 6 of them reasoned out that it was mainly due to religious view. From the total women interviwed,18(5.6\%) . 6\% of the respondent replied that they worry to take care of their current conceived baby due to lack of enough money and $37(11.6 \%)$ respond that they believe that the pregnancy would keep their daily activity and hence affect their lives. Participants were also asked whether their current pregnancy was planned or not, accordingly, 221 (69.1\%) they replied that they were planned to become pregnant, Out of 221 participants who answered that they planned to get the pregnancy, $217(98.2 \%)$ of them said that their plan to get pregnancy were exactly at this time and $4(1.8 \%)$ planned to get pregnant after this year while $99(30.9 \%)$ from the total were not planned.19(5.9\%) $19(5.9 \%$ of respondents reported that they are enforcement to get the current pregnancy either from the husband or family.

About 293(91.6\%) of respondents replied that they feel very pleased on the current pregnancy and $27(8.5 \%)$ feel very upset about their current pregnancy.

Regarding the intentions of women on the current pregnancies $100(31.3 \%)$ of the total participants reported that their recent pregnancies were unintended. Of these with UP $82(82 \%)$ of them replied it is mistimed, and $18(18 \%)$ of them reported that it was unwanted. Of those with Unintended pregnancy, $69(69 \%)$ of them answered that the reason is due to Gods order and 31(31\%) said that it was due to lack of information towards family planning.

Binary and multiple logistic regression analysis were done to analyze factors associated with unintended pregnancy. According to this study, on the binary logistic regression analysis religion, residence, education, occupation, having radio/television, monthly income of the family, distance from the facility, number of pregnancy, number of child alive, decision power, information about UP, using method to prevent, discussion with partner and, previous unintended pregnancy, were associated with unintended pregnancy .For the multiple logistic regression analysis, having radio, not having information about UP, discussion with partner, were identified as predictors of unintended pregnancy (Table 2).

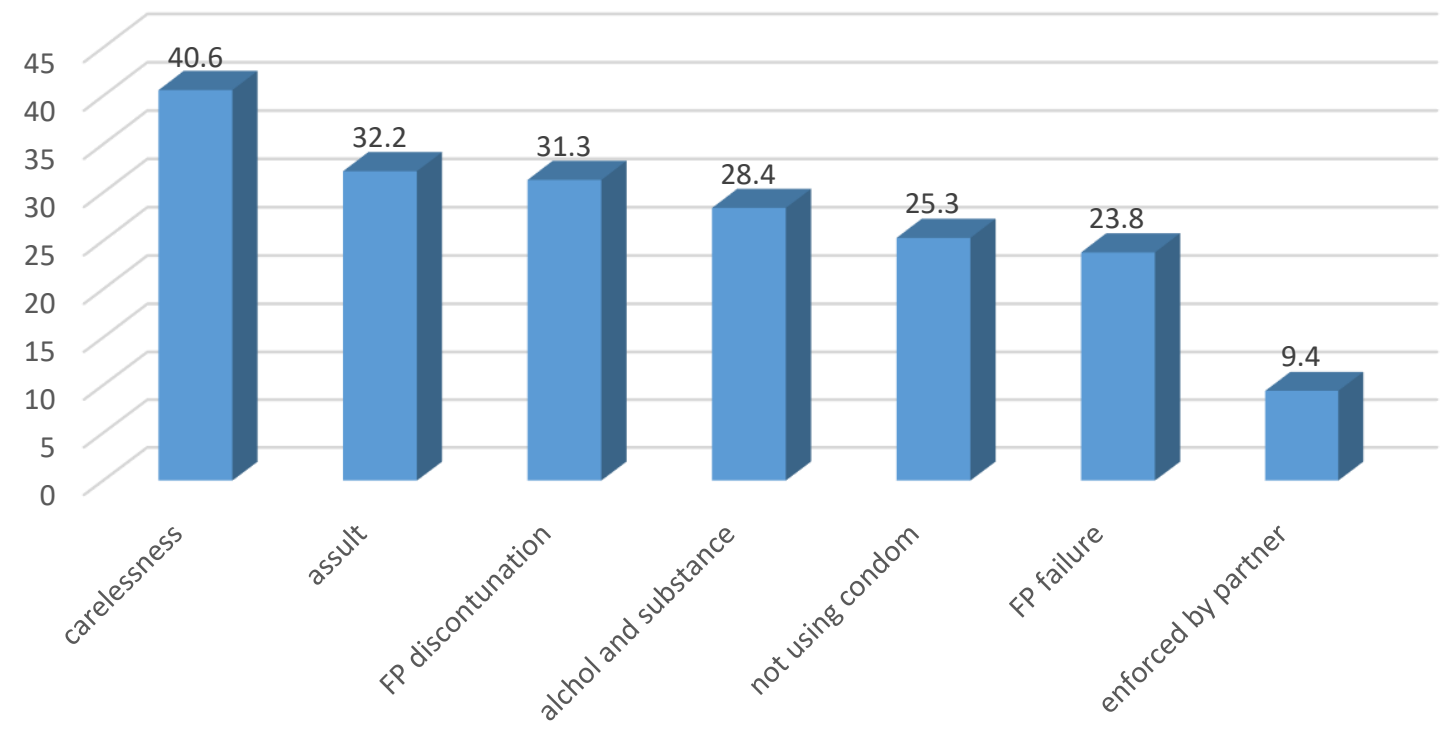

Fig. 1: Reported Causes of Unintended Pregnancy among Pregnant Women Attending ANC in Kersaworeda Eastern Ethiopia, 2015.

Table 2: The Association between Selected Socio- Economic and Demographic Variables and Intention to Recent Pregnancies among Women Attending ANC Kersa, Eastern Ethiopia, $2015(\mathrm{~N}=328)$

\begin{tabular}{|c|c|c|c|c|c|}
\hline \multirow{2}{*}{ Variables } & \multirow{2}{*}{ Category } & \multicolumn{2}{|c|}{ Intention to current pregnancy } & \multicolumn{2}{|l|}{$\mathrm{OR}(95 \% \mathrm{CI})$} \\
\hline & & intended & Unintended & $\mathrm{COR}(\mathrm{CI})$ & $\mathrm{AOR}(\mathrm{CI})$ \\
\hline \multirow{3}{*}{ Religion } & orthodox & $30(136 \%)$ & $4(4 \%)$ & 1 & 1 \\
\hline & Muslim & $173(78.6 \%)$ & $92(92.9 \%)$ & $\begin{array}{l}4.1 \\
(1.41,12.0)\end{array}$ & $\begin{array}{l}4.1 \\
(1.41,12.0)\end{array}$ \\
\hline & protestant & $1(7.7 \%)$ & $1(1 \%)$ & $\begin{array}{l}0.45 \\
(0.04,4.41)\end{array}$ & $\begin{array}{l}0.45 \\
(0.04,4.41)\end{array}$ \\
\hline \multirow[b]{2}{*}{ residence } & urban & $105(47.7 \%)$ & $16(16.2 \%)$ & 1 & 1 \\
\hline & rural & $115(14.3 \%)$ & $83(83.8 \%)$ & $\begin{array}{l}4.78 \\
(2.63,8.68)\end{array}$ & $\begin{array}{l}4.78 \\
(2.63,8.68)\end{array}$ \\
\hline \multirow{4}{*}{$\begin{array}{l}\text { Respondent's education } \\
\text { level }\end{array}$} & uneducated & $109(49.5 \%)$ & $68(68.7 \%)$ & $\begin{array}{l}23.7 \\
(3.18,176.6)\end{array}$ & $\begin{array}{l}23.7 \\
(3.18,176.6)\end{array}$ \\
\hline & primary & $45(20.5 \%)$ & $27(27.3 \%)$ & $\begin{array}{l}22.8 \\
(2.9,175.7)\end{array}$ & $\begin{array}{l}22.8 \\
(2.9,175.7)\end{array}$ \\
\hline & secondary & $28(12.7 \%)$ & $3(3 \%)$ & $\begin{array}{l}3.9 \\
(0.38,39.7)\end{array}$ & $\begin{array}{l}3.9 \\
(0.38,39.7)\end{array}$ \\
\hline & $\begin{array}{l}\text { Diploma, degree and } \\
\text { above }\end{array}$ & $38(17.3 \%)$ & $1(1 \%)$ & 1 & 1 \\
\hline Partner's occupation & Gov't employee & $71(32.3 \%)$ & $4(4 \%)$ & 1 & 1 \\
\hline
\end{tabular}




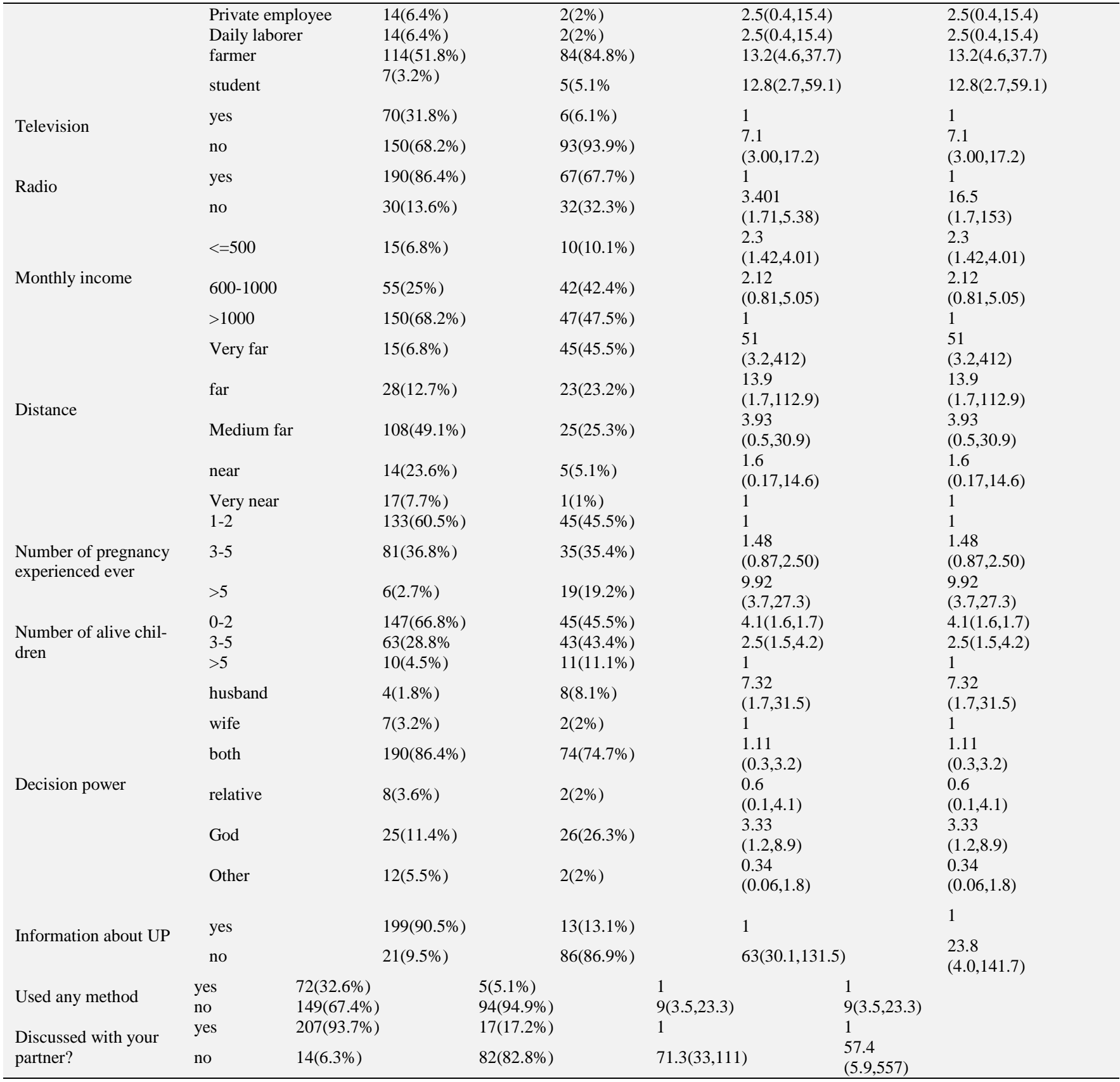

\section{Discussions}

One-third of the study participants reported that their current pregnancy was unintended providing that $81(81.9 \%)$ and $18(11.2 \%)$ were mistimed and unwanted respectively. Having radio, having no information about unintended pregnancy, lack of women decision power, and not discussion with partner found to be predictors of unintended pregnancy.

One out of three women has unintended pregnancy, and this may be attributed to low contraceptive acceptance rate and poor socioeconomic status of the community. Majority of the respondents are Muslim in religion, and different evidence show that intention to use contraceptive is low among Muslims. Weak health care system is another contributing factor for unintended pregnancy for several reasons; for one thing, the infrastructure is low, hence, women may not have accessible, affordable and acceptable contraceptive. Limited number of skilled health personnel is another challenge in the community, and this may lead women to be ignorant in contraceptive acceptance. Similarly, health education given to community is not much powerful to change the existed behavior. There is also men dominated culture in the community as a result the decision power of women is always limited by husband and the community also assume that women are dependent on their male partners that ultimately made women to be fearful for any deviant decision. Low educational status of women is another facilitating factor for unintended pregnancy in that it makes women economically dependent and weak capacity in decision making. The magnitude of unintended pregnancy in this finding is a little bit higher compare to find from Ethiopian Demographic and Health Survey in which only one-fourth of the pregnancies were unintended (ECSA, 2011). This discrepancy may be attributed to difference in study participants in that the EDHS collect data from community based while our data was collected from ANC followers. The difference may also attribute to study area, which is district versus nation. However, our finding was very closer to research finding from Kersa, (Kassa et al 2012). This could be due to similarity in study area because study participants may have similar socioeconomic, cultural and religious background. The two studies also done in a narrow time gab in between in which difference is no more expected.

On the other hand, the prevalence of unintended pregnancy in this study was little lower than the study conducted in Harar town, Eastern Ethiopia (36.3\%), (Solomon et al 2006); this may happen as a result of chronological difference that is the study was con- 
ducted nine years before in which the family planning utilization, and information were low. Similarly, the socioeconomic development was low a decade before that in return affects the health care systems and education in many dimensions.

A research conducted in Damote Gale district, South Ethiopia (15) and in Nepal (Nigatu et al. 2011) found that the unintended pregnancy was $42.4 \%$ and $41.2 \%$ respectively which is about $11 \%$ higher than our study. The difference could be attributed to the progress in awareness due to the time gap between studies, difference in socioeconomic back grounds, and effect of globalization. and availability of services in the current and other factors related to the study areas.

Those participants who have no radio were 16.5 (AOR; CI: 1.7, 153) times more likely to experience unintended pregnancy than that of having radio at home. Radio is one of the most accessible and important tool to create awareness at community. Having radio was found one of the predictors, and the possible reasons are, one, it helps to equip individuals with required information then to understand things differently, second having radio is an expression of wealth status of house hold that is they could have better income than their counterpart. At same, individual with radio may have good health care seeking behavior in response to the information they heard. Study conducted in Nepal (Ramesh et al. 2009) strengthened this finding in that radio exposure reduced unintended pregnancy.

Unintended pregnancy was 23.8 times (AOR 23.8, CI: 4,141) higher among those mothers who have no information about unintended pregnancy than their counterparts. It is obvious that those with no information may not know what to do, even if they may need to await/limit their pregnancy for some time and this is an indication of multi sectors weakness.

The government in general and the health and media sector in particular are expected to disseminate important health information and having information is the first step to bring changes in any aspect including to prevent unintended pregnancy. Lack of information could also an implication of weak health extension worker performance and weak economic status of participants. Being unable to design strategies to address all women in need by district health office might be another contributing factor. Similarity has been observed with study done in Nepal (Ramesh et al. 2009).

This study also revealed that those mothers who did not have decision power on number of children they want in their life time was 7.2 times (AOR: 7.2, CI: 1.7, 31.5) more likely to have unintended pregnancy than those who did have decision power. Meanwhile, those respondents who did not have been discussed with their partner when to conceive their current pregnancy were 54. 4 time (AOR54.4 CI 5.9, 55.7) at high risk to develop unintended pregnancy than those who did have been discussed with their partner.

In the multivariate logistic regression, Age of respondent does not show significant association with unintended pregnancy. However, the proportion of woman experiencing unintended pregnancy was higher among young adults (15-24 years) compared to that adulthood (25-45 years)which is $63 \%$ and $37 \%$ respectively. This finding is in line with the Ethiopian DHS 2011(ECSA, 2011) and the study done in South Ethiopia (Nigatu et al. 2011) and may associated with lack of experience; and women in this age interval may have more enforcement to get pregnancy by their husband because, culturally, if a women did not get pregnancy soon after marriage she is considered as infertile and even may expose to psychological harassment.

\section{Conclusions}

In conclusion, one-third of the ANC followers were with unintended pregnancy providing that mistimed pregnancy takes the highest share $(25.6 \%)$. Four main factors such as absence of radio at household level, having no information about unintended pregnancy, lack of women decision power on number of children they want to have and ever have no discussion on when to conceive the current pregnancy with male partner have identified as predictors of unintended pregnancy. Lack of information on family planning $(10 \%)$, Gods will/order(21.9\%), being enforced by husband $(2.2 \%)$, contraceptive failure $(0.6 \%)$ and sexual assault $(0.6 \%)$ was the associated factor for current unintended pregnancy. Finally, we conclude that no single factor affected unintended pregnancy, rather many factor were interwoven to affect the occurrence of the event.

\section{Competing interests}

This is to declare that we all authors would have no competing interest in this manuscript.

\section{Authors' contributions}

MG has brought the title of the study, has critically revised the study design, data collection techniques and helped the statistical analysis. MA and SW write the proposal, collecting data, and performed statistical analysis. GT and TG thoroughly done the manuscript and contribute to publish the article. All authors read and finally approved this manuscript for submission.

\section{Acknowledgement}

First of all, we would like to thank Haramaya University College of health and medical sciences, department of public health for relentless support. Our deep appreciation and thanks extended to the kersa woreda health bureau, kersa health center and whater health center for their cooperation. Last but not least we would like to extend our gratitude to all participants of this study for their cooperation and kind response.

\section{References}

[1] World Health Organization,(2007) Engaging men in changing gender based inequality in health:program intervention,

[2] Stanford J, Trussell J, and Vaughan B, (1999) National Survey of Family Growth, Family Planning Perspectives "Are all contraceptive failures unintended pregnancies?”, 31(5):p 212-247 \& 260

[3] Cabral R, Curtis K, Hatfield-Timajchy K, Gilbert BC, Rochat R, and Santelli J,(2003) The Measurement and Meaning of Unintended Pregnancy: Perspectives on Sexual and Reproductive Health., 35(2):p94-101. https://doi.org/10.1363/3509403.

[4] Burke AE, McDonald-Mosley R, and Tsui AO,(2010) Family Planning and the Burden of Unintended Pregnancies. Oxford University Press. 32(1):114-74.

[5] Gipson JD, Hindin MJ and Koenig MA, (2008) the Effects of Unintended Pregnancy on Infant, Child, and Parental Health: A Review of the Literature. Studies in Family Planning. 39(1):18-38. https://doi.org/10.1111/j.1728-4465.2008.00148.x.

[6] Hearst N, Malarcher S, and Olson LG, (2010) Unintended Pregnancy and Pregnancy Outcome: Equity and Social Determinants. Public Health Programs. Geneva, Switzerland: World Health Organization; p. 177- 97.

[7] Holcombe E, Logan C, Manlove J, Ryan S.(2007) The Consequences of Unintended Childbearing: The National Campaign to Prevent Teen Pregnancy Child Trends.

[8] PAI.Washington,(2011) "Why Population Matter to Maternal Health": Population Action International Healthy Family Healthy Planet.

[9] Bankole A, Hussein R, Sedgh G, SingnsS, Wulf B, (2009) Decade of uneven progress, Abortion World Wide. New York: Guttmacher Institute.

[10] Guttmacher Institute (2010) Benefits of Meeting the contraceptive Needs of Ethiopian Women. Series, number 1: 4.

[11] Ethiopian central statistics agency (ECSA) (2011) Fertility references and Family planning: Ethiopian Demographic and Health Survey, Addis Ababa, Ethiopia: 81-108.

[12] Kassa N, Berhane Y, Worku A, (2012) Predictors of Unintended Pregnancy in Kersa, Eastern Ethiopia, 2010. Reproductive Health Journal. 9(1) 
[13] Solomon W, Mesganaw F, (2006) unintended pregnancy and induced abortion in a town with accessible family planning services: The case of Harar in eastern Ethiopia. Ethiop J Health Dev; 20(2):79-83

[14] Ramesh A, Kusol S, Pramote P, (2009) correlates of unintended pregnancy among currently pregnant married women in Nepal. BMC Int Health Hum;9(17)

[15] Nigatu R.,Tadele K, (2011) A population based study on unintended pregnancy among married women in a Gale district in Southern Ethiopia Journal of Geography and Regional Planning.; 4(7):417-27. 